\title{
New content in The BMJ
}

\section{BMJ Voices}

BMJ Voices is a collection of readers' experiences of working in the NHS. For this, The BMJ is seeking short audio submissions from UK readers. These submissions will be published on thebmj.com. If you would like to contribute to this collection, please email a brief audio recording to

voices@ bmj.com or phone +44 (20) 30587427 and follow the instructions. Please include your name, job title, and place of work.

\section{If I Ruled the NHS}

If I Ruled the NHS is a new series that invites guest contributors to offer their remedy for problems in the health service. The $B M J$ is seeking provocative, polemic style opinion pieces of around 450 words that put forward a clear argument on an issue of the author's choice. The $B M J$ will be publishing these in print and online between January and May. If you are interested in submitting, please email Gareth Iacobucci (giacobucci@bmj.com) or call +44 (20) 78740738.

Cite this as: BMJ 2015;350:h304

๑ BMJ Publishing Group Ltd 2015 